Int. J. Dev. Biol. 52: 267-278 (2008)

doi: $10.1387 / \mathrm{ijdb} .072318 \mathrm{~mm}$

\title{
Follicular cell differentiation in polytrophic ovaries of a moth midge, Tinearia alternata
}

\author{
MARTA MAZURKIEWICZ and JANUSZ KUBRAKIEWICZ* \\ Department of General Zoology, Zoological Institute, University of Wroclaw, Wroclaw, Poland
}

\begin{abstract}
Dipteran ovaries consist of structural-functional units termed egg chambers. Each egg chamber is composed of a cluster of germ cells enveloped by a simple somatic follicular epithelium. With the progress of oogenesis, initially an almost uniform population of follicular cells (FCs) becomes diversified into a few subgroups, which significantly differ in their function and behaviour. From the extensive genetic and molecular studies on Drosophila it became evident that the mode of diversification of FCs and the interactions between distinct FC subpopulations and the germ-line cells are essential for a proper course of oogenesis and the generation of oocyte/ embryo polarity. Recent comparative studies showed that major dipteran lineages may significantly differ in the mode of FC differentiation. The most essential difference occurs in the ability of the FCs to undertake migrations within the egg chamber. In contrast to long distance, invasive migrations characteristic of distinct FC subgroups in the egg chambers of the most derived flies (Brachycera), including Drosophila, the FCs in the ovaries of more ancestral Nematocera lack migratory activity and change their location only within the epithelial layer. Comparative analyses indicate that the FCs in the representatives of particular evolutionary lineages within Nematocera may differ in their behaviour during oogenesis. In this report we describe the FC differentiation pathway in the egg chambers of a moth midge, T. alternata (Psychodomorpha). Comparison with representatives of craneflies (Nematocera: Polyneura) showed that differences in the behaviour of FCs and in the number of FC subpopulations between Polyneura and Psychodomorpha, may depend on different oogenesis dynamics. In spite of the observed differences, some functional homologies between distinct subsets of the FCs in dipteran ovaries are postulated.
\end{abstract}

KEY WORDS: follicular cells, polytrophic ovaries, Diptera, Nematocera, Psychodidae

\section{Introduction}

Insect ovaries are composed of elongated tubes termed ovarioles. Two major ovary types, panoistic and meroistic ovaries are distinguished on the basis of significant differences in the ovariole architecture. The meroistic ovary is subdivided into two additional subtypes: polytrophic and telotrophic (for classification of insect ovaries see: Büning, 1994; Bilinski, 1998). In a polytrophic ovary each ovariole is composed of structural-functional units termed egg chambers. The egg chamber consists of germ and somatic cells. Germ cells form a cluster (clone) within which they differentiate into an oocyte and its accompanying polyploid nurse cells. Germ cell cluster is encased by a simple somatic follicular epithelium. In the course of oogenesis, initially uniform population of follicular cells (FCs) becomes progressively and coordinately diversified into several specialized subgroups. Particular subgroups occupy distinct positions within the egg chamber. They also differ in their morphology and activity, and participate in the formation of different parts of an elaborate and regionally specialized eggshell.

Our knowledge of mechanisms that govern cell differentiation is based on the data obtained from the studies of model organisms. Meroistic-polytrophic ovarioles are characteristic for all dipterans, including Drosophila. The mode of differentiation of

Abbreviations used in this paper: aPC, anterior polar cells; aTC, anterior terminal follicular cells; FC, follicular cell; mbFC, mainbody follicular cell; mfAT, micropylar forming anterior terminal follicular cell; $\mathrm{NC}$, nurse cell; OO, oocyte; pPC, posterior polar cell; pTC, posterior terminal follicular cell.

\footnotetext{
*Address correspondence to: Dr. Janusz Kubrakiewicz. Department of General Zoology, Zoological Institute, University of Wroclaw, Sienkiewicza 21, 50335 Wroclaw, Poland. Tel: +48-71-375-4021. Fax: +48-71-322-2817. e-mail: jkubrak@biol.uni.wroc.pl
}

Published online: 14 February 2008 

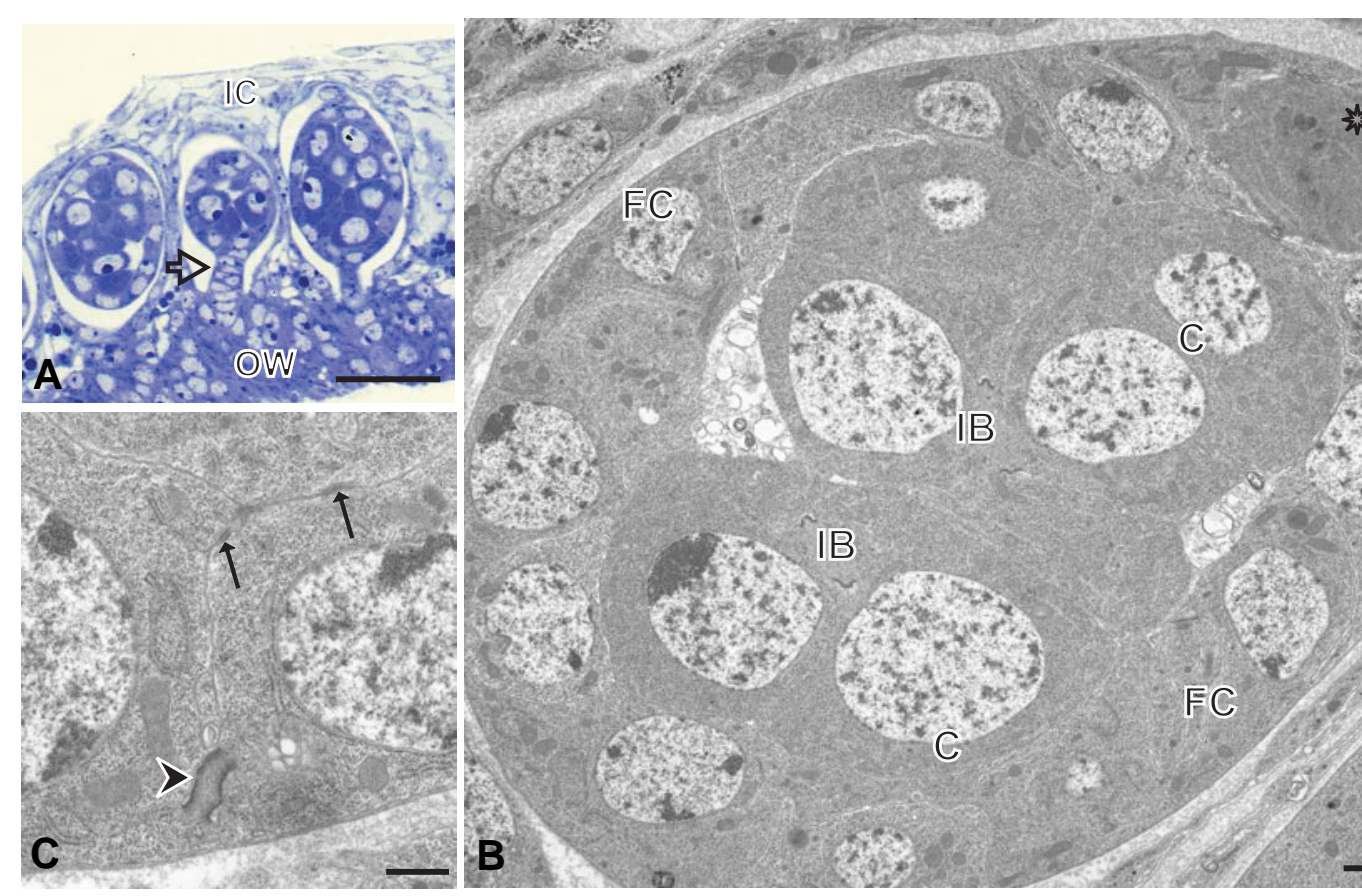

IB
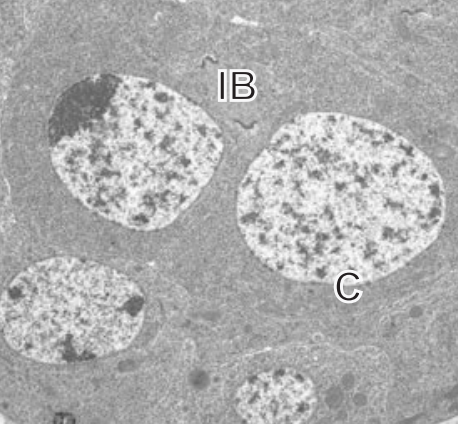

Fig. 1. Egg chambers in the larval ovary (undifferentiated stage). (A) Semithin section of the ovary cortex. The egg chambers are encompassed by the interstitial somatic cells (IC) of the ovary cortex. Each egg chamber is linked by the ovariole stalk (hollow arrow) with the thickened wall of the swollen oviduct calyx (OW). Scale bar, 20 um. (B) Low magnification electron micrograph showing the cluster of undifferentiated germ cells $(C)$ invested by a simple layer of undifferentiated follicular cells (FC). Asterisk denotes dividing follicular cell. IB, intercellular bridges connecting germ cell within the cluster. Scale bar, $2.5 \mu \mathrm{m}$. (C) Apically follicular cells are linked by adherens junctions (arrows). Occasionally intercellular bridges (arrowhead) can also be observed. Scale bar, 0.6 um

somatic FCs in Drosophila ovary was found essential for a proper course of oogenesis and the generation of embryonic polarity (Ray and Schüpbach, 1996; Deng and Bownes, 1998; Dobens and Raftery, 2000; López-Schier, 2003; Steinhauer and Kalderon, 2006). Drosophila ovary is an excellent, genetically tractable model system to study the mechanisms of epithelial tissue morphogenesis. The extensive genetic and molecular studies on Drosophila ovaries provided a sound basis for the contemporary understanding of mechanisms that underlie such fundamental events of tissue morphogenesis as cell specification, migration and epithelial-mesenchymal transitions (EMT) (Ribeiro et al., 2003 Rørth 2002; Fulga and Rørth, 2002; Pacquelet and Rørth, 2005; Schober and Perrimon, 2002; Montell, 2003, 2006).

In Drosophila ovaries FCs' differentiation begins at the initial stages of egg chamber development. The egg chamber is formed when the cluster of germ cells buds off from the germarium and becomes invested by a simple follicular layer. After being shifted to the vitellarium, consecutively formed egg chambers are separated from each other by stacks of a few somatic cells (so called interfollicular stalks). The first to be specified within the follicular epithelium are polar cells (PCs) - two pairs of FCs situated at the anterior and posterior poles of the egg chamber (Grammont and Irvine, 2001; Bai and Montell, 2002; Besse and Pret, 2003; Torres et al., 2003; Althauser et al., 2005). PCs differ from the rest of the epithelium. Although they sit within the epithelial layer they are not supported by the basal lamina but border directly on the interfollicular stalk cells. PCs also cease their divisions early, round up and do not exhibit apical-basal polarity. Their activity concentration-dependent manner, the anterior terminal cells become subdivided into three well defined subpopulations (border, stretched and centripetal cells) (Grammont and Irvine, 2002; Denef and Schüpbach, 2003; Xi and McGregor, 2003). The ultimate fate of each of these subpopulations depends on their position within the epithelium. Cells neighbouring the anterior PCs become border cells, those in more distant position stretch over the nurse cell compartment, while those located most distantly from the source of a differentiating signal transform into centripetal cells. Predetermined subpopulations of FCs start their differentiation by significantly changing their shape, and their position within the egg chamber. These changes result either from the translocation the FCs undergo within the epithelial layer, or from long distance migrations that require detachment from the epithelium and invasion of germ cell compartment. Border cells are delaminated from the anterior of the egg chamber and, having formed a rosette surrounding the anterior PCs, invade the nurse cell complex. They actively migrate between the nurse cells toward the anterior pole of the oocyte (Niewiadomska et al., 1999; Duchek and Rørth, 2001; Lehman, 2001; Fluga and Rørth, 2002; Geisbrecht and Montell, 2002; Rørth, 2002; Montell, 2003). Resting on the oocyte surface they contribute to the formation of a micropyle, a specialized region of the eggshell that enables sperm entry during fertilization (Zarani and Margaritis, 1985; 1991). Simultaneously with the border cell migration, FCs on the surface of the egg chamber move posteriorly. Most of the FCs come in touch with the growing vitellogenic oocyte and become columnar mainbody FCs. About 50 FCs located in the anterior 
position, stretch and flatten over the nurse cells. FCs that form a narrow ring located between the stretched and mainbody FCs penetrate centripetally along the border between the nurse cells and the oocyte. In the final stages of oogenesis the nurse cell cytoplasm is rapidly transported into the ooplasm, while the oocyte is entirely enclosed by the FCs, which produce and secrete the eggshell (Deng and Bownes, 1998; Dobens and Raftery, 2000; Horne-Badovinac and Bilder, 2005).

Knowledge of the molecular pathways that cause FCs' differentiation processes comes from the extensive analyses of FCs' behaviour in the ovaries of wild type and mutant Drosophila. In Drosophila, distinct FCs' subgroups are not only well defined morphologically but can be directly recognized by molecular markers - antibodies or probes raised against specific gene expression products. Unfortunately these markers are unavail- able for other dipteran species. Thus, all we know about the process of FCs differentiation in other species is essentially based on morphological data and comparisons made with Drosophila as the model system.

Flies (Diptera) represent one of the largest and most diversified insect order. According to a widely accepted opinion the Diptera are traditionally divided into two major subgroups: more ancestral and paraphyletic Nematocera, comprising usually small and delicate flies with long multisegmented antennae, and monophyletic, advanced Brachycera (true flies), usually more robust flies with short, generally 3-segmented antennae (Oosterbroek and Courtney, 1995; Yeates, 2002; Wiegmann et al., 2003).

Drosophila belongs to Cyclorrhapha, the most derived group within the true flies (Yeates, 2002; Wiegmann et al., 2003). In order to gain insight into the evolution of mechanisms of FCs

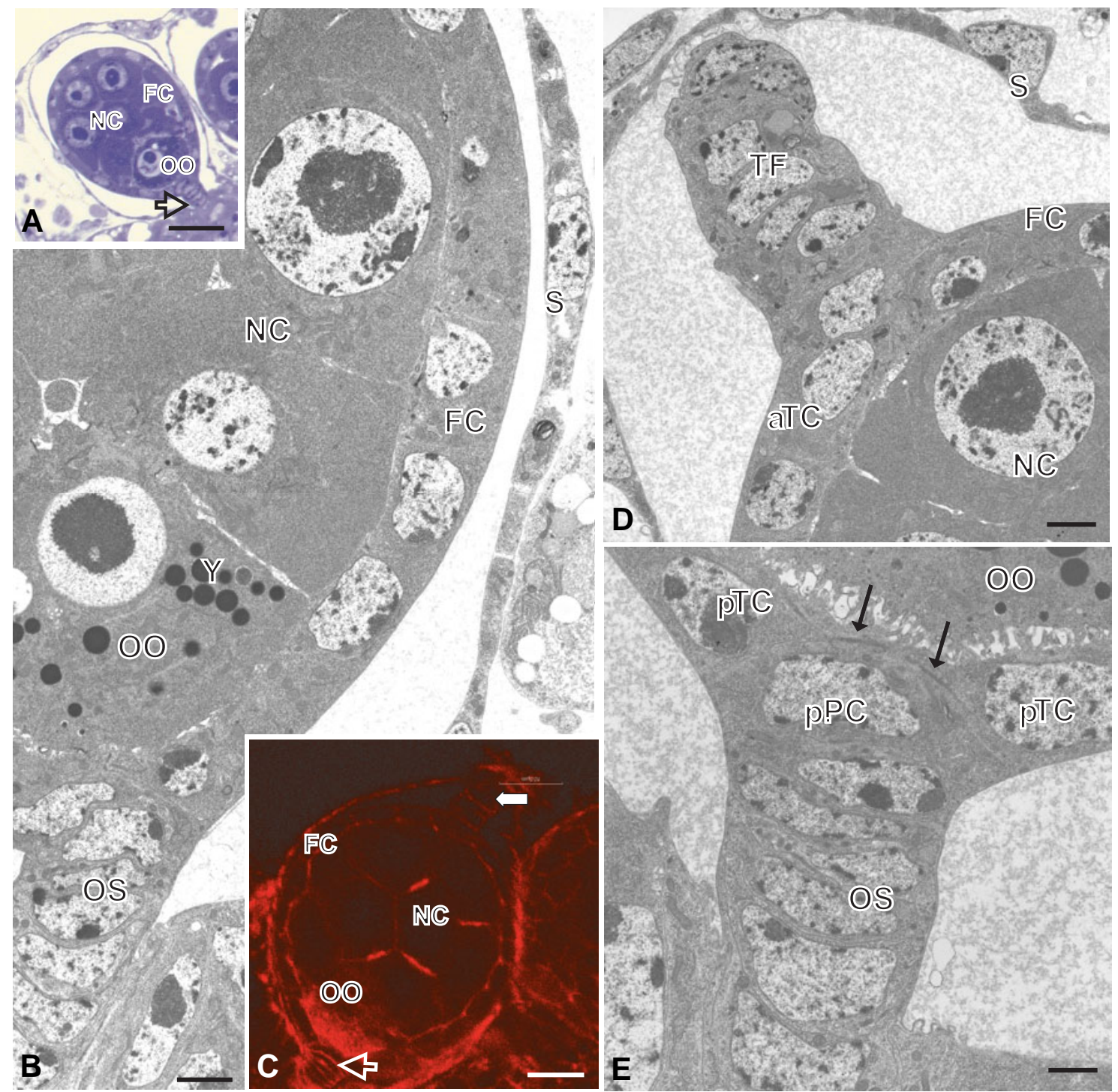

Fig. 2. Egg chambers in the pupal ovary (early vitellogenesis). (A) Semithin section through the egg chamber shows that the germ cells have diversified into posteriorly located oocyte (OO) and nurse cells (NC) occupying the anterior part of the egg chamber. Note that all germ cells are of almost equal size. A uniform layer of follicular cells (FC) covers the germ cell cluster. Hollow arrow indicates the ovariole stalk. Scale bar, $10 \mu \mathrm{m}$. (B) Low magnification electron micrograph showing fragments of the lateral and posterior part of the egg chamber. A uniform layer of follicular cells (FC) covers both the nurse cells (NC) and the oocyte (OO). Note the first yolk spheres (Y) in the ooplasm. OS, ovariole stalk; $S$, ovariolar sheath. Scale bar, $1.7 \mu \mathrm{m}$. (C) Early vitellogenic egg chamber after rhodamine-conjugated phalloidin staining viewed with the confocal microscope. Stalked cells of terminal filament (thick arrow) and ovariole stalk (hollow arrow) can clearly be seen at both extremities of the egg chamber. Scale bar, $10 \mu \mathrm{m}$. (D,E) Electron micrographs showing the stalked cells of the terminal filament (TF) at the anterior pole of the egg chamber (D) and similar organization of the ovariole stalk cells (OS) at the posterior pole (E). Note that the follicular cells at the anterior and posterior apices of the egg chamber are broadly connected with the cells of the terminal filament and ovariole stalk, respectively. They are also tightly linked by adherens junctions with their neighbouring cells of the follicular epithelium (adherens junctions are denoted by arrows in E). NC, nurse cells; OO, oocyte; OS, ovariole stalk; aTC, anterior terminal cells; pTC, posterior terminal cells; pPC, posterior polar cell; S, ovariolar sheath. Scale bars, $1.1 \mu$ m. 


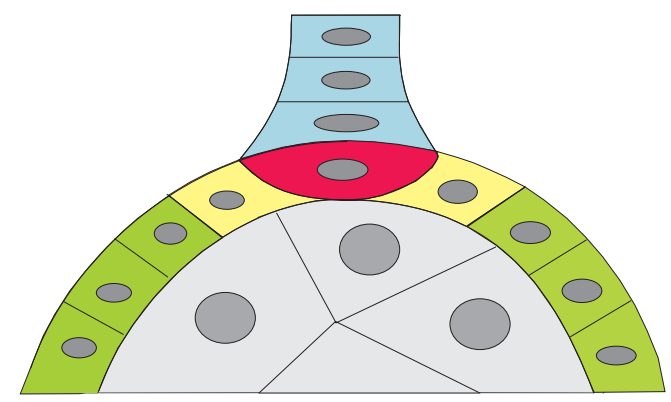

\begin{tabular}{|l}
$\square$ anterior PCs \\
$\square$ anterior terminal FCs \\
$\square$ cuboidal FCs \\
$\square$ stalk cells (terminal filament or interfollicular stalk cells) \\
$\square$ nurse cells
\end{tabular}

Fig. 3. The arrangement of follicular cell (FC) subpopulations at the anterior pole of the early and mid vitellogenic egg chamber. Different cells are indicated by colors.

morphogenesis comparative studies have been undertaken within a wider phylogenetic context. The first two reports were devoted to FCs' differentiation within Brachycera (Kubrakiewicz et al., 2003; Tworzydlo et al., 2005). Data obtained from the studies of several representatives of the lower Brachycera (= Orthorrhapha) were compared with the well-known scenario of morphogenetic events that take place during FCs differentiation in Drosophila egg chambers. The most essential difference in the mode of FCs differentiation was found in the ability of FCs to migrate within the egg chamber. While in Drosophila and other Cyclorrhapha some subpopulations of $\mathrm{FCs}$ undertake long distance migrations, among Orthorrhapha there is only one group of FCs, the border cells, that exhibit migratory behaviour and invade germ cell cluster. The analyses of FCs differentiation have recently been extended to the representatives of the ancestral Nematocera. Nematocera are highly diversified and comprise about 70,000 presently identified species subdivided into 26 families (Oosterbroek and Courtney, 1995). Within the Nematocera four distinct evolutionary lineages are distinguished: (Tanyderomorpha + Psychodomorpha), Neoneura, Polyneura and Anisoneura (Krzeminski and Krzeminska, 2003). Previous analyses of the FCs differentiation in craneflies, the representatives of Tipulomorpha and Trichoceridae that belong to Polyneura, and other nematocerans (Mazurkiewicz and Kubrakiewicz, 2005; Wenzel et al., 1990; Kubrakiewicz et al., 1998; Mazurkiewicz and Kubrakiewicz, unpublished results) identified the basic rules of FCs morphogenesis for the whole group. FCs of the Nematocera do not exhibit migratory activity and thus do not change significantly their position within the egg chamber throughout oogenesis. Their "intraepithelial translocations" result from the changes in the cell shape. The ovary organization and the mode of its development were found to be essentially the same in all nematoceran species studied so far (Kubrakiewicz et al., 1998). Particular taxa may, however, exhibit significant differences in the course of oogenesis. The major difference in this respect relates to the contribution of the nurse cells to the oocyte growth. For instance, in species representing Polyneura the oocyte seems to be at least partially self sufficient, while the nurse cells are small and degenerate early during oogenesis (Lima-de-Faria, 1962; Lima-de-Faria and Moses, 1966; Büning, 1994; Mazurkiewicz and Kubrakiewicz, 2002). In other groups (e.g. Psychodomorpha) the oocyte growth depends largely on the transcriptional activity of the prominent, highly polyploid nurse cells, which function until the final stages of oogenesis (Mazurkiewicz and Kubrakiewicz, 2001).

Our contemporary knowledge on FCs differentiation pathways in Nematocera is mainly based on the studies of the representatives of Polyneura. In this study we present the results of the detailed morphological analysis of follicular epithelium morpho-
Fig. 4. Egg chambers at mid vitellogenesis. (A) At mid vitellogenesis, the oocyte (OO) becomes larger than its accopmanying nurse cells (NC) and occupies almost half of the egg chamber volume. Follicular epithelium (FC) is equally thick over the whole surface of the egg chamber. Semithin section. Scale bar, $20 \mu \mathrm{m}$. (B,C) Electron micrographs show that the cuboidal follicular cells in contact with the nurse cells (FC in B) form a tight epithelial cover, while those covering the oocyte surface (FC in C) change their shape, round up a bit and so intercellular spaces appear among them (asterisk). In contact with the oocyte, follicular cells form microvilli ( $m v$ in $C$ ) which interdigitate with the microvilli formed by the oolemma. S, ovariolar sheath. Scale bars, $1.7 \mu \mathrm{m}$.
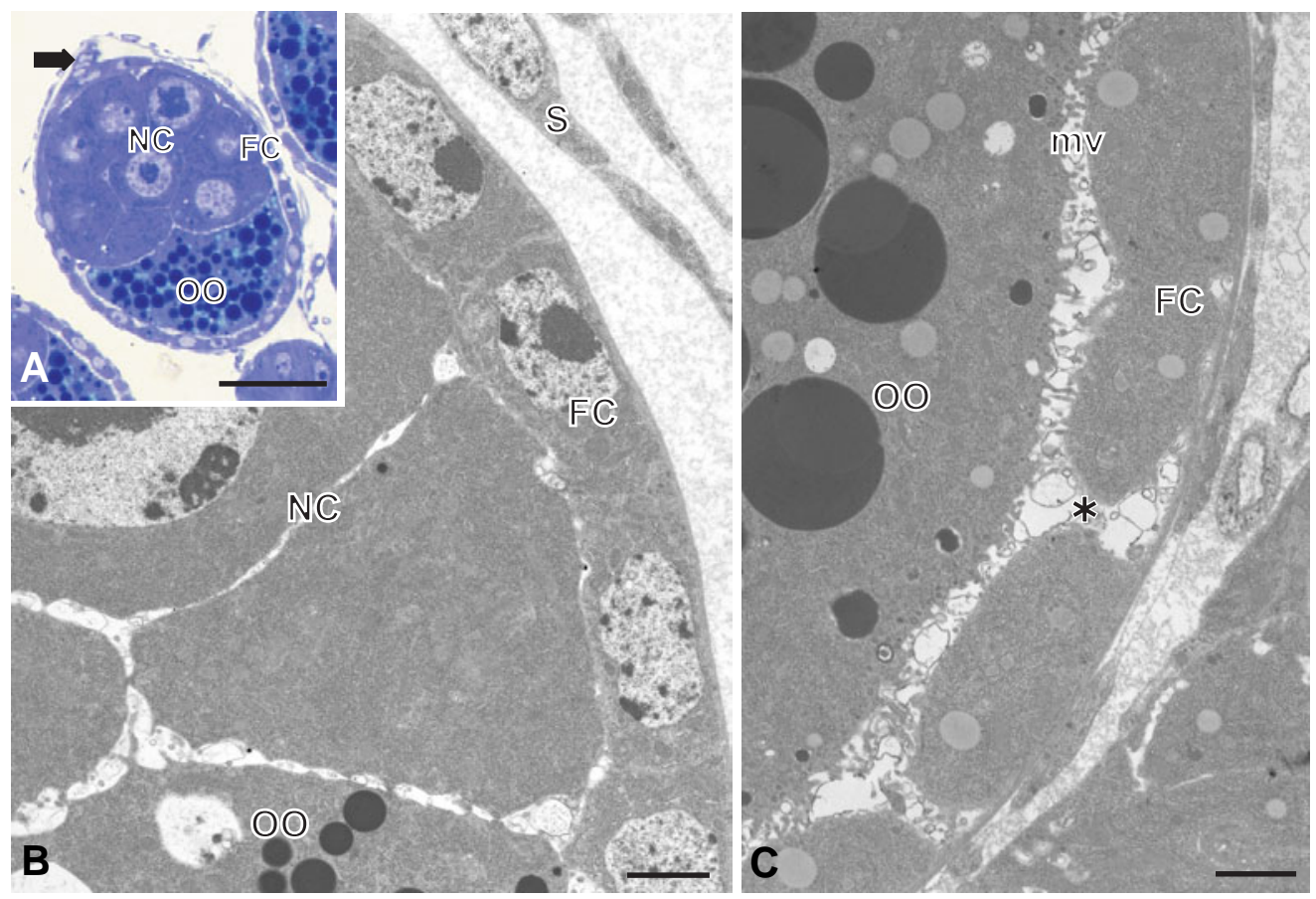
genesis in a moth midge, Tinearia alternata, which belongs to Psychodomorpha. We believe that comparisons between phylogenetically distant nematoceran groups, as well as between the Nematocera and Brachycera will shed some new light on the evolution of the mechanisms that govern morphogenesis of the follicular epithelium in Diptera, and may also contribute to our better understanding of some general mechanisms of epithelial tissue differentiation.

\section{Results}

\section{Morphology of ovaries in the adult female}

Paired ovaries of Tinearia consist of a few dozen (50-70) developmentally synchronized meroistic-polytrophic ovarian tubes (ovarioles). The ovarioles are relatively short. Each ovariole contains only one functional egg chamber (Figs $1 \mathrm{~A}, 2 \mathrm{~A})$. The egg chamber consists of a cyst $-\mathrm{a}$ cluster of 16 germ cells (cystocytes) interconnected by cytoplasmic bridges (Fig. 1B). Within

Fig. 5. Egg chambers at advanced vitellogenesis (A) The egg chamber has considerably grown but the relative proportion of the oocyte and nurse cells has not changed and so the oocyte (OO) still occupies half of the egg chamber volume. The follicular cells over the nurse cell compartment (NC) have become significantly stretched (black arrows), with the exception of those located at the anterior pole of the egg chamber (arrowhead). The latter contribute to the formation of the micropylar plate (hollow arrow). n, oocyte nucleus (germinal vesicle). Semithin section. Scale bar, 20 um. (B) DAPI stained whole mount preparation shows regularly spaced, numerous mainbody follicular cells ( $\mathrm{mbFC}$ ) and only a few stretched ones (arrows) over the nurse cell compartment (NC). Fluorescence microscopy. Scale bar, $20 \mu \mathrm{m}$. (C) Electron micrograph showing the anterior pole of the egg chamber. The material of the micropylar plate ( $\mathrm{mp}$ ) is synthesized by micropylar forming anterior terminal follicular cells (MfAT) and deposited onto the anterior surface of the nurse cells (NC). Arrows indicate the secretory granules in the cytoplasm of the micropylar forming anterior terminal follicular cells. Scale bar, $1.1 \mu \mathrm{m}$. (D) The follicular cells that contribute to the formation of the micropylar plate (mp) are apically tightly joined by adherens (solid arrows) and septate (hollow arrow) junctions. Scale bar, $0.6 \mu \mathrm{m}$. (E) Processes of three anterior polar cells (arrows) exhibit strong signal after Alexa 488-conjugated phalloidin staining indicating high microfilament contents. Whole mount preparation of the anterior pole of the egg chamber. NC, nurse cells. Fluorescence microscopy. Scale bar, $10 \mu \mathrm{m}$ the cluster cystocytes are diversified into an oocyte and its sibling 15 highly polyploid nurse cells. The cluster is invested by a simple follicular epithelium (Figs 2A, B). Like in other dipterans, each ovariole in Tineariais polarized along the anterior-posterior axis ${ }^{1}$. The anterior end of the ovariole consists of a terminal filament ${ }^{2}$, while the ovariole stalk (pedicle) forms the ovariole posterior end. The ovariole stalk is directly linked to the wall of a swollen, bulbshaped calyx of the lateral oviduct (Figs 1A, 2E). The terminal filament and the pedicle are formed by an assemblage of flattened cells stacked one on the top of the other and thus resembling a
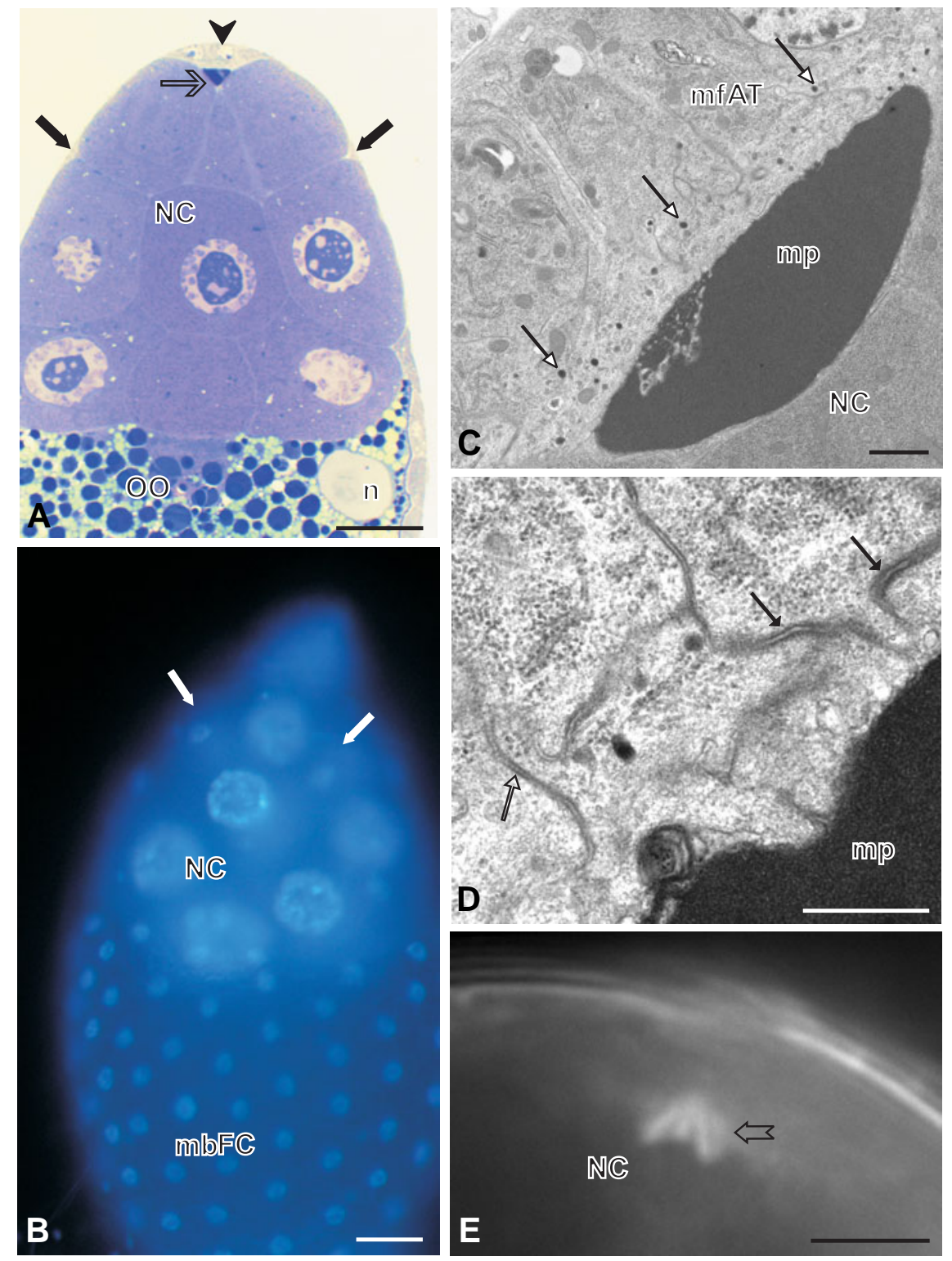

Note 1: Since in Tinearia the oviduct calyx is located centrally and the ovarioles protrude in all directions, their longitudinal axes do not align with the anterior-posterior body axis as they do in the ovaries of other flies (including Drosophila). This unusual position of the ovarioles within the body cavity of Tinearia is the result of the peculiar location, size and function of the oviduct calyx (for details see: Mazurkiewicz and Kubrakiewicz, 1998). There is no doubt, however, that the longitudinal axes of ovarioles in all dipteran ovaries are homologous. That is why for the clarity of comparisons presented here we will refer to the anterior-posterior polarity of Tinearia ovarioles, although it does not reflect the real situation.

Note 2: Due to differences found in ovariole formation between Drosophila and the Nematocera, their terminal filaments cannot be considered as homologous structures. 
stalk of coins (Figs $2 \mathrm{C}-\mathrm{E}$ ). Although the majority of ovarioles contain only one egg chamber, the ovarioles located in the posterior part of the ovary contain two egg chambers. However, in these ovarioles only the posterior egg chamber is functional and undergoes normal development while the anterior egg chamber arrests at the early stages of development and eventually degenerates. The egg chambers within the ovariole are connected by a stalk of a few, flat, interfollicular cells stacked exactly in the same way as those forming the terminal filament or ovariole stalk.

\section{Egg chamber development and stages of oogenesis}

The initial stages of germ cell cluster formation and development of ovarioles in Tinearia take place exclusively during larval stages. Moreover, the formation of cystocyte clusters precedes the appearance of ovarioles (for details of ovary development in Tineariasee: Koch, 1929; Mazurkiewicz and Kubrakiewicz, 1998). In the larval gonad, the clusters of dividing germ cells become invested by a simple somatic epithelium and thus form the egg chambers (Fig. 1A). Concurrently, terminal filaments and ovariole pedicles differentiate which results in the emergence of the definite structure of the ovarioles (Figs $2 \mathrm{~B}-\mathrm{E}$ ). The ovarioles are covered by a simple squamous epithelium (ovariole sheath) and are encased by a meshwork of extended interstitial cells (Fig. 1A). In the late larvae, the egg chambers house yet undifferentiated germ cells. The cystocytes diversify in the pupal ovary. Although within the given egg chamber all cystocytes have the same size, they are morphologically different. (Fig. 2A). Posteriorly located oocyte initiates vitellogenesis and accumulates yolk, while the remaining cystocytes differentiate into polyploid nurse cells, each containing spherical nucleus with a single, prominent nucleolus surrounded by polytene chromosomes (Figs 2A, B). With the progress of yolk accumulation, the oocyte becomes conspicuously larger, and in the more advanced pupae it occupies half of the egg chamber volume (Fig. 4A). Subsequent period of a sudden growth of the egg chamber coincides with the emergence of an adult female. The vitellogenic oocyte comprises half of the egg chamber volume, while the other half is occupied by nurse cells (Figs 5A, B). This ratio changes dramatically in the final stages of oogenesis when the nurse cell contents are rapidly transferred into the oocyte during a process termed "nurse cell dumping" (for details of the massive nurse cell cytoplasm transport during oogenesis in Tinearia, see: Mazurkiewicz and
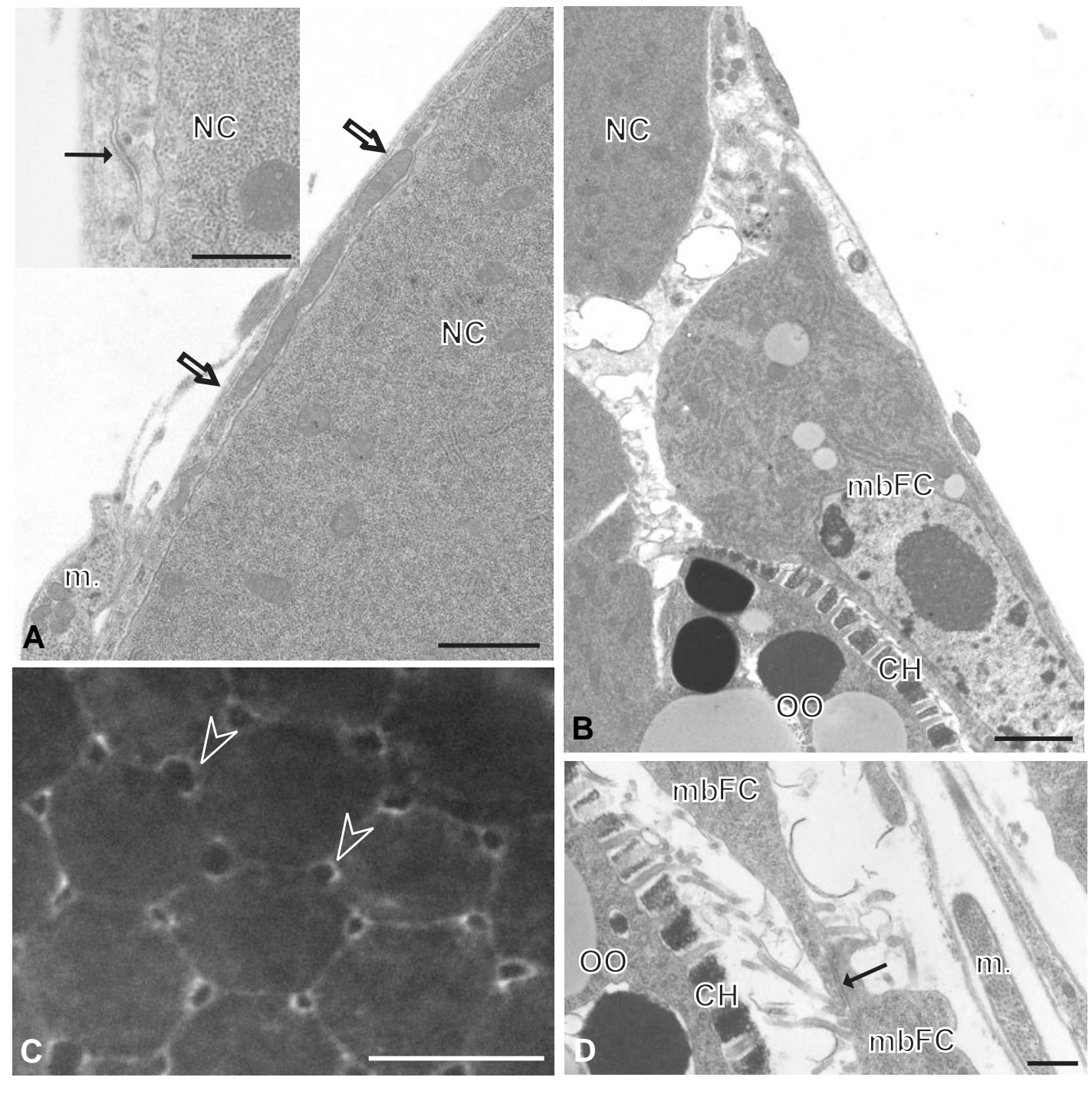

Fig. 6. Follicular cells in the advanced vitellogenic egg chamber. (A) Electron micrograph showing thin layer of follicular cells (arrows) stretched over the nurse cell compartment (NC). Insert in the upper left corner shows stretched cells joined by adherens junctions (arrow). m, muscle fiber. Scale bars, 1.1 $\mu \mathrm{m}(\mathrm{A})$ and $0.6 \mu \mathrm{m}$ (insert). (B) Electron micrograph taken from the lateral aspect of the nurse cell-oocyte border shows the anteriormost ring of mainbody follicular cells (mbFC) covering the vitellogenic oocyte (OO) surface. The oolemma still forms regular microvilli, while the surface of the mbFC facing the oocyte is smooth. $\mathrm{CH}$, material of egg envelopes covering the oocyte surface; NC, nurse cells. Scale bar, $1.7 \mu \mathrm{m}$. (C) Staining of the mbFC layer with Alexa 488conjugated phalloidin shows hexagonal pattern of follicular cell distribution. Regularly spaced "holes" located "at the corners" of follicular cells are indicated by arrowheads. Fluorescence microscopy. Whole mount preparation. Scale bar, $20 \mu \mathrm{m}$. (D) In places where mbFC contact each other, adherens junctions (arrow) occur. $\mathrm{CH}$, material of egg envelopes; $m$, muscle fibres on the surface of the ovariole; 00, oocyte. Electron micrograph. Scale bar, $0.6 \mu \mathrm{m}$. 

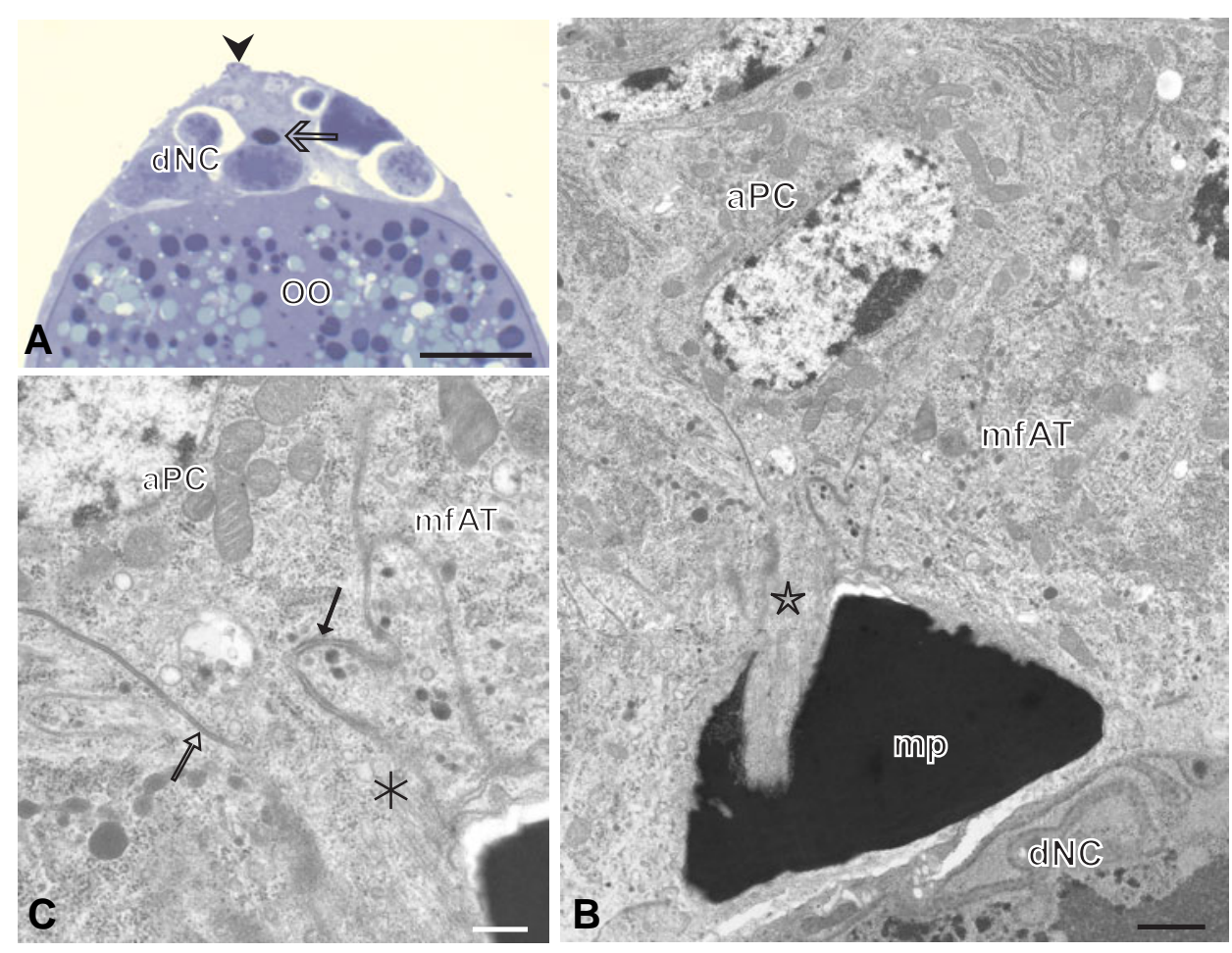

Fig. 7. Egg chamber at the stage of choriogenesis. (A) After nurse cell dumping (rapid transfer of nurse cell cytoplasm into the oocyte), the nurse cell compartment significantly diminishes and the remnants of the nurse cells degenerate ( $d N C$ ). Concurrently, the micropylar plate (hollow arrow) is shifted towards the anterior pole of the oocyte (OO). Arrowhead points to the micropyle forming follicular cells. Semithin section. Scale bar, $20 \mu \mathrm{m}$. (B,C) Each of the three anterior polar cells $(a P C)$ sends an elongated process (hollow asterisk) that would mould the canal in the micropylar plate (mp). $d N C$, degenerating nurse cell; mfAT, micropyle forming anterior terminal cells. Follicular cells that contribute to the formation of the micropyle are apically joined by adherens (arrow) and septate (arrow) junctions. Asterisk denotes a bunch of microfilaments. Scale bars, $1.1 \mu \mathrm{m}(B), 0.4 \mu \mathrm{m}(C)$.
Kubrakiewicz, 2001). Almost completely devoid of their cytoplasm, nurse cells degenerate and are eliminated by programmed cell death (Kazmierczak et al., in preparation).

For the clarity of description of FC differentiation, the whole process of oogenesis in Tinearia has been arbitrarily subdivided into a few discrete stages based on the observations presented above (Table 1).

\section{Differentiation of follicular cells}

In order to follow the whole process of FCs differentiation we had to analyze the subsequent stages of egg chamber development starting from the moment when they appear in the cortex of the larval ovary until the final steps of oogenesis in the adult. From the initial stages of ovariole development, the egg chambers are polarized along the anterior-posterior axis. This polarity is marked by the presence of an anterior terminal filament (or interfollicular stalk) and posteriorly located ovariole stalk (Figs 2C-E). The germ cells within the egg chamber remain undifferentiated until late larval stages (Figs 1 A, B). At that time the FCs form a one cell thick epithelial cover around the germ cell cluster and divide mitotically (Fig. 1B). Although the FCs are roughly cuboidal, their shapes are not fully regular (Fig. 1B). Neighbouring FCs are apically joined by adherens junctions, and some of them are occasionally connected by interfollicular bridges (Fig. 1C). By the time the diversification of germ cells within the egg chamber becomes morphologically evident, most FCs have regular cuboidal shape (Figs 2AC). Until that stage of oogenesis the follicular epithelium consists of three morphologically distinguishable subpopulations of cells. Most of them form the cuboidal epithelium over the major part of the egg chamber surface (Figs 2B, C). There are, however, two other subpopulations located symmetrically at anterior and posterior poles of the egg chamber. These are polar cells and their neighbouring terminal cells (Figs 2D, E). Polar cells (PCs) are placed within the follicular epithelium at the extremities of the egg chamber and border directly on either the cells of the terminal filament (or interfollicular stalk) (anterior polar cells) or on the cells of the ovariole stalk (posterior polar cells) (Fig. 2E). In contrast to the cuboidal FCs, which are supported by the basal lamina, the contact of the PCs with the basal lamina is limited. PCs adhere broadly to the cells of the stalks and expose their slightly convex apical surfaces towards the germ cells (nurse cells at the anterior and the oocyte at the posterior pole of the egg chamber) (Fig. 2E). Apposing directly to the lateral aspects of the PCs, terminal cells

TABLE 1

\section{STAGES OF OOGENESIS IN TINEARIA}

\begin{tabular}{|c|c|c|}
\hline $\begin{array}{l}\text { Stage of ontogenetic } \\
\text { development }\end{array}$ & Stage of oogenesis & \\
\hline larva & undifferentiated & $\begin{array}{l}\text { germ cell cluster enveloped by a simple } \\
\text { layer of somatic follicular epithelium. Most } \\
\text { FCs are undifferentiated and may divide } \\
\text { mitotically }\end{array}$ \\
\hline pupa & early vitellogenesis & $\begin{array}{l}\text { equally sized germ cells diversified into } 15 \\
\text { polyploid nurse cells and } 1 \text { oocyte; first yolk } \\
\text { spheres in the ooplasm; follicular epithe- } \\
\text { lium of uniform thickness; FCs may still } \\
\text { undergo mitotic divisions }\end{array}$ \\
\hline late pupa & mid vitellogenesis & $\begin{array}{l}\text { vitellogenic oocyte occupies half of the egg } \\
\text { chamber volume; follicular epithelium of } \\
\text { uniform thickness; FCs do not divide any- } \\
\text { more }\end{array}$ \\
\hline \multirow[t]{2}{*}{ imago } & advanced vitellogenesis & $\begin{array}{l}\text { vitellogenic oocyte occupies half of the egg } \\
\text { chamber volume; main body FCs cover the } \\
\text { surface of the oocyte; nurse cell compart- } \\
\text { ment enveloped by stretched FCs }\end{array}$ \\
\hline & choriogenesis & $\begin{array}{l}\text { nurse cell cytoplasm rapidly transferred into } \\
\text { the oocyte; vitellogenic oocyte, now occu- } \\
\text { pying the major part of the egg chamber } \\
\text { volume, covered by slightly extended main } \\
\text { body FCs }\end{array}$ \\
\hline
\end{tabular}



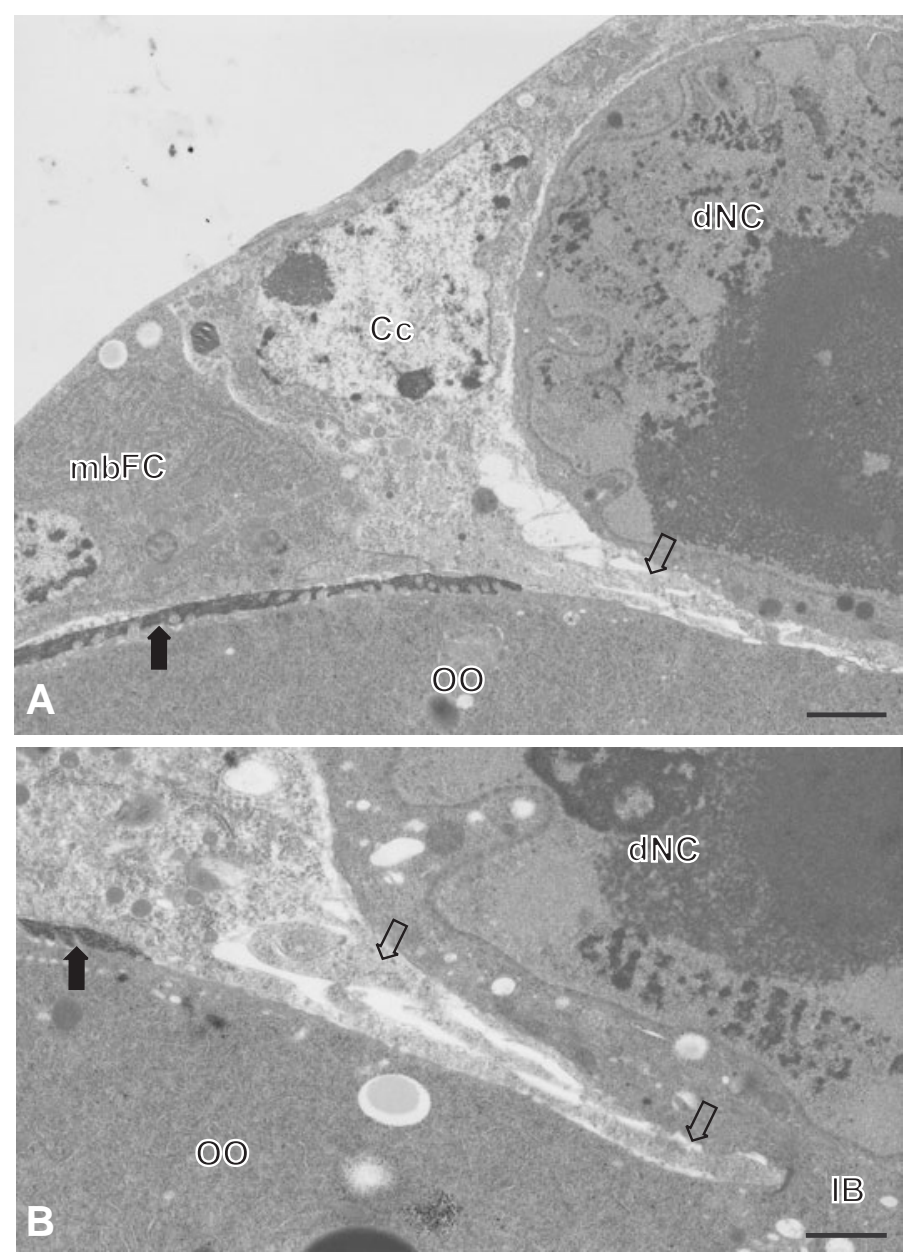

Fig. 8. Egg chamber at the stage of choriogenesis. (A,B) Electron micrographs showing the border of the oocyte $(\mathrm{OO})$ and the degenerating nurse cells (dNC). Note the presence of follicular cells (Cc) that sit over the mainbody follicular cells ( $\mathrm{mbFC}$ ) and form long processes (hollow arrows) invading the nurse cell/oocyte interface. These processes reach the intercellular bridges (IB) connecting the nurse cells with the oocyte (in $B)$. Black solid arrows indicate the chorion deposited on the oocyte surface by mainbody follicular cells. Scale bars, $1.7 \mu \mathrm{m}(A), 1.1 \mu \mathrm{m}(B)$.

adopt their shape to the convex apical surface of the PCs and thus may be distinguished from the surrounding cuboidal cells (the arrangement of FCs at the anterior pole of the egg chamber is schematically presented on Fig. 3). All cells within the follicular epithelium are joined by adherens junctions (Fig. 2E).

With the progress of oogenesis, the oocyte accumulates more and more yolk and becomes conspicuously larger than the nurse cells and in mid vitellogenesis it occupies half of the egg chamber volume (Fig. 4A). Immunodetection of mitotic markers (phosphorylated histone $\mathrm{H} 3$ ) showed that at this stage, the FCs still proliferate (data not shown). The cells that cover the nurse cell compartment remain cuboidal (Fig. 4B), while those adhering to the oocyte surface (mainbody FCs) change their shape (Fig. 4C). They round up and so are not tightly apposed to each other. This results in the formation of intercellular spaces between cells and this part of the follicular epithelium becomes incoherent (= exhibits patency) (Fig. 4C). Mainbody FCs form numerous microvilli that interdigitate with the microvilli formed by the oocyte surface
(Fig. 4C). Although the FCs change their shapes, the thickness of the follicular epithelium remains uniform over the whole egg chamber until mid vitellogenesis (Figs 4A-C).

The most evident differences among follicular cell subpopulations appear during the next phase of egg chamber growth (advanced vitellogenesis) that occurs just after emergence of an imago. The egg chambers in the ovary of the young adult attain their final volume and are three times larger than those in the preceding developmental stage. In spite of such spectacular growth, the ratio between the volume of the nurse cell compartment and that of the oocyte remains unchanged indicating that both the nurse cells and the oocyte contribute equally to the growth of the egg chamber (Figs 5A, B). Since the FCs do not divide any more they must adapt to this sudden growth of the egg chamber. Most of them gather over the oocyte surface and thus become mainbody FCs (Fig. 5B). A few of those that are left in contact with the nurse cells stretch and become squamous (Figs $5 A, B ; 6 A)$. The thickness of the epithelial cover over the egg chamber is thus not uniform. A small group of cells located at the anterior tip of the egg chamber does not undergo stretching. These are anterior PCs surrounded by anterior terminal cells (Fig. $5 \mathrm{~A})$. At the advanced stages of vitellogenesis these cells contribute to the formation of a micropyle (micropylar plate). The micropylar plate is deposited at the anterior pole of the egg chamber and thus lies on top of the nurse cell compartment just below the anterior terminal FCs and PCs (Figs 5A, C). Anterior terminal cells contain several secretory vesicles filled with dense material which indicates that they produce and secrete the material of the micropyle (Fig. 5C). Three anterior PCs send posteriorly directed projections that mould the canals in the forming micropylar plate. Analysis of whole mounts stained with fluorochrome-conjugated phalloidin showed that these projections are enriched with $\mathrm{F}$-actin (microfilaments) (Fig. 5E). Bunches of microfilaments (Fig. 7C) and several microtubules (not shown) in the projections were also observed during TEM analysis. During micropyle formation, the anterior terminal FCs and PCs are tightly joined by the apical junctional complexes (adherens and septate junctions) (Fig. 5D).

By the time the micropylar plate is initially deposited at the anterior pole of the nurse cell compartment, the mainbody FCs are engaged in the formation of the main part of the eggshell. Electron dense material of the mainbody chorion forms a layer of uniform thickness over the whole surface of the vitellogenic oocyte. This chorionic material is penetrated by numerous microvilli formed by the oocyte (Figs 6B, D). Mainbody FCs are slightly extended and form regular hexagonal pattern (Fig. 6C). Although connected by adherens junctions (Fig. 6D) they are not closely adjoined and intercellular spaces can still be observed at the corners of neighbouring cells (Fig. 6C). Adherens junctions can also be found among those cells that stretch over the nurse cell compartment (Fig. 6A - insert). Since the stretched and mainbody FCs strikingly differ in their thickness, the border between both subpopulations, and the anteriormost ring of the mainbody FCs are clearly visible (Fig 6B).

At the final stages of oogenesis the nurse cell cytoplasm is rapidly injected into the oocyte, which leads to a drastic reduction in the volume of the nurse cell compartment and increase in the oocyte volume. Nurse cell nuclei shrink and condense (Fig. 7A). Starting with the "terminal injection" the nurse cells initiate programmed cell death. Rapid shrinkage of the nurse cells results in 
a shift of the forming micropylar plate from its previous position at the top of the egg chamber towards the anterior pole of the oocyte (Figs 7A, B). Although the micropylar plate becomes closer to the anterior pole of the oocyte, the micropyle forming FCs do not actively migrate but rather passively change their position in relation to the choriogenic oocyte (Fig. 7B). They remain still tightly linked by the adherens and septate junctions (Fig. 7C). Sudden reduction in the nurse cell volume results also in the relaxation of the stretched cells. They cover degenerating nurse cells but can also be found between them (data not shown). Stretched cells eventually degenerate together with the nurse cells.

Soon after the nurse cell dumping yet another subpopulation of FCs appear in the egg chamber. A single ring of distinct FCs encompasses the border between the degenerating nurse cells and the oocyte (Fig. 8A). These cells differ from the adjoining mainbody FCs. They do not participate in chorion synthesis but form elongated projections that penetrate the nurse cell/oocyte interface. These centripetally directed projections ultimately lie at the walls of the intercellular bridges that still connect the nurse cells with the oocyte (Fig. 8B). The centripetally oriented FCs are apically joined with the mainbody FCs by the adherens junctions. That is why when the projections elongate, the mainbody FCs seem to be dragged behind centripetally and during the final stages of oogenesis the anterior pole of the choriogenic oocyte is covered by the mainbody FCs (data not shown). When the micropyle seals the mainbody chorion, the egg cell becomes entirely enclosed by the eggshell.

The fate of both posterior polar and posterior terminal cells is not clear. Posterior pole of the eggshell in Psychodidae is not equipped with any specialized chorionic structure (see: Rocha et al., 2003; our own observations) so it seems probable that the FCs occupying the posterior domain of the egg chamber eventually adopt the fate of the mainbody FCs and contribute to the formation of the mainbody chorion.

\section{Discussion}

The mechanisms that govern the patterning of FCs during egg chamber morphogenesis have been best characterized in Drosophila melanogaster. Subdivision of initially uniform population of undifferentiated FCs into several subgroups of different morphology, activity and fate, results from early, position-dependent FCs specification followed by subsequent inductive signalling between both germ and somatic FCs, but also among FCs themselves. Specified FC subpopulations undergo coordinated migrations and change their position within the egg chamber. Within their new location sites they contribute to the formation of region specific parts of the eggshell (Dobens and Raftery, 2000; Waring, 2000). Migrations and spatial rearrangements of distinct FC subsets have yet another functional significance. Some of the migrating FCs secrete signals that play a pivotal role in the establishment of the asymmetry of the egg cell and thus determine the polarity of the future embryo (López-Schier, 2003; Steinhauer and Kalderon, 2006).

Insight into the evolution of mechanisms that underlie FCs' morphogenesis can only be gained in the comparative studies. Unfortunately, the analyses of FCs differentiation process in flies other than Drosophila lack genetic background and molecular screening and comparative studies rely almost exclusively on morphological data. Detailed comparative observations clearly indicate that the major dipteran subgroups may significantly differ in the mode of their FC differentiation. The essential difference relates to the migratory abilities of FCs within the egg chamber (Kubrakiewicz et al., 2003; Mazurkiewicz and Kubrakiewicz, 2005, Tworzydlo et al., 2005). The "invasive" migrations, but also extensive planar movements of FCs appeared to be specific only for the representatives of evolutionarily advanced true flies (Cyclorrhapha), including Drosophila. Even among lower brachycerans (Orthorrhapha) migratory activity of FCs is significantly reduced. In their egg chambers only border cells actively migrate. However, their migratory behaviour differs from that exhibited by border cells in the egg chambers of cyclorrhaphan flies. In the latter case, border cells detach from the epithelium and migrate among the functional nurse cells towards the oocyte anterior pole. In contrast, in the egg chambers of lower brachycerans, the border cells migration is facilitated by the progressive degradation of the nurse cell complex. No other translocations of FCs have been described in lower brachycerans (Kubrakiewicz et al., 2003, Tworzydlo et al., 2005). Their FCs neither stretch nor migrate centripetally, but rather maintain their position within the epithelium throughout oogenesis. Tworzydlo et al. (2005) reported that the FCs in lower brachycerans may change their relative position within the epithelium. This change, however, does not result from the FCs migratory activity, but depends on the specific behaviour of the oocyte. The oocyte forms anteriorly directed lamellipodium-like protrusions that penetrate between the nurse cells and their overlaying FCs. As a result, one-third of the nurse cell compartment may be enveloped by the protrusions, while the number of FCs that come in contact with the oocyte increases.

As far as the migratory behaviour of FCs is concerned, the differences between Nematocera and Brachycera are even better pronounced than those among lower and higher brachycerans. The FCs in the egg chambers of the Nematocera never invade the interior of the egg chamber, while the only alternations in their

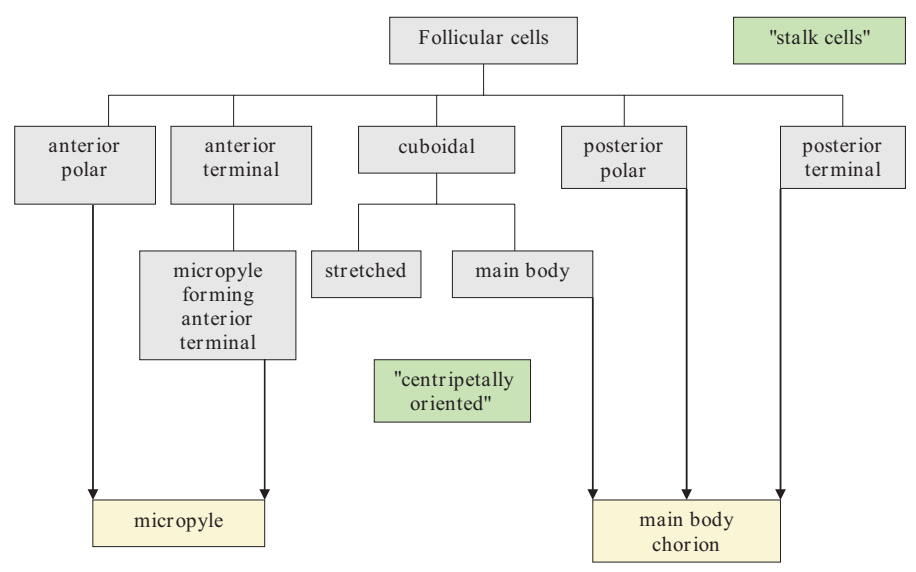

Fig. 9. Diagram showing the subdivision of the FCs in the egg chambers of Tinearia ("stalk cells" comprise the cells of the terminal filament (or the interfollicular stalk) at the anterior pole of the egg chamber and the cells of the ovariole pedicle at its posterior end. The origin of the "stalk cells" and the "centripetally oriented FCs" is not clear, so they were not linked to the remaining part of the diagram. 
ultimate position result from cell shape modifications and/or short range translocations within the epithelium. Previous comparative studies and data presented here indicate that this rule of FCs "immobility" is followed by all studied Nematocera. Since the FCs do not migrate within the egg chamber, the number of the specialized FC subpopulations is usually relatively low. For instance, contrary to the presence of eight, well-defined FC subpopulations in Drosophila (based on the data presented by: Margaritis, 1985; for a review see: Deng and Bownes, 1998; Dobens and Raftery, 2000; Horne-Badovinac and Bilder, 2005), the egg chambers of the recently studied cranefly species contain only four subsets of FCs: anterior and posterior PCs, anterior terminal cells and the mainbody FCs. Among anterior terminal cells two additional subgroups were distinguished based on their different function. Those that neighbour the anterior polar cells were found to participate in the micropyle formation, and thus have been referred to as micropyle forming anterior terminal cells, while all the remaining anterior terminal cells adopt the mainbody fate and contribute to the secretion of the mainbody chorion (Mazurkiewicz and Kubrakiewicz, 2005).

Although the Nematocera share the common mode of FCs differentiation, representatives of particular evolutionary lineages may deviate from the basic differentiation pattern. Detailed morphological analysis indicates that the FCs in the Nematocera may differ in their behaviour during oogenesis. In consequence, the number of distinguished FC subsets can also be different. In this paper we show that some subpopulations of FCs in the moth midge ovaries do not have counterparts in the egg chambers of craneflies (Polyneura: Tipulomorpha, Trichoceridae) (Fig. 9). Interestingly, these subpopulations exhibit some similarities to the well-defined FCs subgroups in Drosophila and other advanced true flies. Different behaviour of the FCs during egg chamber morphogenesis observed in the craneflies and moth midges seems to be caused by different dynamics of their nurse cells activity. In craneflies, the nurse cells remain relatively small and do not seem to contribute considerably to the oocyte growth, while the oocyte nucleus, equipped with the extrachromosomal amplified ribosomal genes (=rDNA), is large and transcriptionally active during oogenesis. Oocyte growth coincides with the progressive reduction of the nurse cell size (Büning, 1994; Mazurkiewicz and Kubrakiewicz, 2002). In the advanced stages of vitellogenesis the germ cell cluster breaks up. The individual nurse cells become invested by the columnar anterior terminal FCs and eventually disintegrate within the follicular epithelium. As a result, the FCs at the anterior pole of the egg chamber face the anterior pole of the vitellogenic oocyte. In this position they produce and secrete the material of the micropyle (Mazurkiewicz and Kubrakiewicz, 2005). The situation described above contrasts with that found in the egg chambers of moth midges. Their nurse cells are conspicuously highly polyploid and transcriptionally active. During early stages of oogenesis they considerably grow and occupy a large portion of the egg chamber. These nurse cells function definitely longer and are eliminated much later than those of craneflies (Mazurkiewicz and Kubrakiewicz, 2001). Since the FCs do not invade the germ cell compartment, the micropylar plate is formed at the anteriormost pole of the egg chamber, with no direct contact with the oocyte. Prolonged activity of nurse cells and their considerable contribution to the oocyte growth in Tinearia results not only in the micropyle being formed away from the oocyte, but also in the change in the appearance of additional FC subpopulation(s). At the time of rapid growth of the egg chamber (advanced vitellogenesis) most FCs reside over the oocyte (mainbody FCs). A small group of more anteriorly located FCs stretch over the increasing surface of the nurse cells. Stretched cells in Tineariaresemble those described in the egg chambers of Drosophila and other higher true flies. In Drosophila, with the onset of vitellogenesis (stage 8/9), there is a dynamic and coordinated translocation of the follicular epithelium towards the posterior end of the egg chamber - the process known as the "posterior migration". The FCs that acquire contact with the oocyte (mainbody FCs) undergo transition from cuboidal to columnar morphology (Deng and Bownes, 1998; Dobens and Raftery, 2000; Horne-Badovinac and Bilder, 2005). In contrast to the situation described in Drosophila, the mainbody FCs in moth midges remain cuboidal in shape. Since their translocation coincides with the sudden growth of the oocyte, they probably have to accommodate the rapid increase of the oocyte surface and that is why they retain their cuboidal shape or are slightly extended. The cellular mechanisms that drive FCs stretching and posterior migration in Drosophila, as well as those involved in the translocation of FCs in Tinearia egg chambers during advanced vitellogenesis are unknown. Nevertheless stretched FCs in Drosophila and Tinearia egg chambers may be regarded as homologous.

In the final stages of oogenesis in Tinearia, when the nurse cell cytoplasm is rapidly injected into the oocyte and the nurse cell volume is drastically reduced, the anterior pole of the oocyte is progressively enclosed by the centripetally oriented, cellular extensions of the FCs that are located at the nurse cells/oocyte border. The FCs with centripetally expanded processes have also been found in the egg chambers of lower brachycerans (Kubrakiewicz et al., 2003; Tworzydlo et al., 2005) and were regarded as the anteriormost mainbody FCs. The origin of FCs with centripetally oriented extensions in Tinearia is presently unclear. They certainly differ from the mainbody FCs in that they are not engaged in mainbody chorion deposition. Data presented in this paper suggest that these cells might drag the mainbody FCs over the anterior pole of the oocyte. From the functional point of view centripetally oriented FCs in Tineariamay thus be considered homologous to the centripetal FCs in the egg chambers of the advanced true flies.

In our previous report (Mazurkiewicz and Kubrakiewicz, 2005) we showed that the micropyle forming anterior terminal FC and the anterior PCs in craneflies have their counterparts in the brachyceran border cells and anterior PCs, respectively. Analyses presented in this study indicate unequivocally that the similar functional homology exists between the micropyle forming anterior terminal FC and the anterior PCs in Tinearia and those of craneflies and brachycerans.

Results of detailed morphological studies of the FCs differentiation in various dipteran species presented recently (Kubrakiewicz et al., 2003; Mazurkiewicz and Kubrakiewicz 2005, Tworzydlo et al., 2005), together with data obtained in this study, confirm earlier suggestions that:

1. Diptera developed a specific system of the anterior-posterior patterning of their follicular epithelium. This patterning is manifested by the early emergence of the PCs at both extremities of the egg chamber. Although PCs are located within the epithelium, they contact directly the stalk cells that do not belong to the 
epithelium. Stacks of stalk cells usually intervene between the neighbouring egg chambers (interfollicular stalks), but they may as well form the terminal filament of the ovariole (at the anterior end) or the ovariole pedicle (at the posterior end).

2. invasive migration of FCs i.e. translocation that requires delamination of FCs from the epithelial layer and their further movement within germ cell compartment, appeared late during dipteran evolution and is characteristic for the most derived dipteran taxa (Brachycera).

3. some functionally homologous subpopulations of FCs can be encountered in various dipteran species regardless of their systematic position.

\section{Materials and Methods}

\section{Flies}

Specimens of Tinearia alternata (Say) came from the laboratory culture. Flies were reared at room temperature in plastic vials filled with wet decaying nettle leaves. Ovaries used in this study were dissected from the late larvae, pupae and adult females.

\section{Histology and electron microscopy}

Ovaries were dissected and fixed at RT in $2.5 \%$ glutaraldehyde in the $0.1 \mathrm{M}$ phosphate buffer $(\mathrm{pH}=7.4)$ for a few weeks. The material was rinsed for several times with the phosphate buffer and postfixed in the mixture containing $1 \%$ osmium tetroxide and $0.8 \%$ potassium ferrocyanide for 1 $\mathrm{hr}$ (according to McDonald, 1984). After dehydratation in a graded series of acetone the material was embedded in Epon 812. Semithin sections ( $0.6 \mu \mathrm{m}$ thick) were stained with $1 \%$ methylene blue and examined with an Olympus BHS microscope. Ultrathin sections were contrasted with uranyl acetate and lead citrate according to the standard methods and examined with a Zeiss EM 900 electron microscope at $80 \mathrm{kV}$.

\section{Histochemical procedures}

The ovaries were dissected and fixed in $4 \%$ formaldehyde freshly prepared from paraformaldehyde in phosphate-buffered saline PBS ( $\left.\mathrm{NaCl}, 137 \mathrm{mM} ; \mathrm{KCl}, 2.7 \mathrm{mM} ; \mathrm{Na}_{2} \mathrm{HPO}_{4}, 8 \mathrm{mM} ; \mathrm{KH}_{2} \mathrm{PO}_{4}, 1.5 \mathrm{mM}\right)$. After a few rinses with the PBS the material was subjected to whole mount fluorescent staining.

For detection of microfilaments (F-actin) the ovaries were stained with $0.2 \mu \mathrm{g} / \mathrm{ml}$ phalloidin conjugated to either phalloidin (Sigma) or Alexa 488 (Molecular Probes) for $20 \mathrm{~min}$. in darkness and then thoroughly rinsed with PBS. For detection of cell nuclei (DNA) the material was stained with $0.2 \mu \mathrm{g} / \mathrm{ml}$ DAPI (4',6 diamidino-2 phenylindole dihydrochloride) (Sigma Chemical Co., St. Louis, MO, USA) for 20 min. in darkness. After rinsing with the buffer, the ovarioles were whole-mounted onto microscope slides and examined with an Olympus BHS epifluorescence microscope or with an Olympus JX-70 equipped with a Fluoview 500 confocal device.

The estimation of proliferating activity of the follicular cells was based on morphological detection of cells undergoing mitosis or on the results of immunostaining with anti-phosphorylated histone $\mathrm{H} 3$, a specific marker of mitotic cells. In the latter case the ovaries were fixed in $4 \%$ formaldehyde in PBS containing $0.1 \%$ Triton $\mathrm{X}-100$. After several rinses in the same buffer first with and then without Triton $X-100$ the material was incubated for an hour at $+37^{\circ} \mathrm{C}$ in a blocking solution (PBS with $1 \% \mathrm{BSA}$ ) and then directly transferred to solution containing a primary antibody, an anti-phospho-histone $\mathrm{H} 3$ (rabbit lgG) (Sigma) (1:500) overnight at $+4^{\circ} \mathrm{C}$. Subsequently the material was rinsed in PBS and incubated for $1 \mathrm{hr}$ at $37^{\circ} \mathrm{C}$ in a solution containing the secondary antibody: anti-rabbit $\lg \mathrm{G}$ conjugated to TRITC (Sigma) (1:400). After a few rinses with PBS fragments of disrupted ovaries or dissected ovarioles were mounted on microscope slides and examined with an Olympus BHS epifluorescence microscope equipped with an appropriate filter. Control reactions fol- lowed the same procedure but the treatment with the primary antibody was omitted.

\section{Acknowledgements}

We would like to thank Sylwia Nowak for her excellent technical assistance.

\section{References}

ALTHAUSER, C., JORDAN, K.C., DENG, W., RUOHOLA-BAKER, H. (2005) fringe-dependent Notch activation and tramtrack function are required for specification of polar cells in Drosophila oogenesis. Dev.Dyn. 232: 1013-1020.

BAI, J., MONTELL, D. (2002). Eyes Absent, a key repressor of polar cell fate during Drosophila oogenesis. Development 129: 5377-5388.

BESSE, F., PRET, A.M. (2003). Apoptosis-mediated cell death within the ovarian polar cell lineage of Drosophila melanogaster. Development 130: 1017-1027.

BILINSKI, S.M. (1998). Introductory remarks. Folia Histochem. Cytobiol. 36: 143145.

BÜNING, J. (1994). The Insect Ovary. Ultrastructure, Previtellogenic Growth and Evolution. Chapman \& Hall, London.

DENEF, N., SCHÜPBACH, T. (2003). Patterning: JAK-STAT signaling in the Drosophila epithelium. Curr. Biol. 13: 388-390.

DENG, W., BOWNES, M. (1998). Patterning and morphogenesis of the follicle cell epithelium during Drosophila oogenesis. Int. J. Dev. Biol. 42: 541-552.

DOBENS, L.L., RAFTERY, L.A. (2000). Integration of epithelial patterning and morphogenesis in Drosophila ovarian follicle cells. Dev. Dyn. 218: 80-93.

DUCHEK, P., RØRTH, P. (2001). Guidance of cell migration by EGF receptor signalling during Drosophila oogenesis. Science 291: 131-133.

FULGA, T.A., RøRTH, P. (2002). Invasive cell migration is initiated by guided growth of long cellular extensions. Nature Cell Biol. 4: 715-719.

GEISBRECHT, E.R., MONTELL, D.J. (2002). Myosin VI is required for E-cadherinmediated border cell migration. Nat. Cell. Biol. 4: 616-620.

GRAMMONT, M., IRVINE, K.D. (2001). fringe and Notch specify polar cell fate during Drosophila oogenesis. Development 128: 2243-2253.

GRAMMONT, M., IRVINE, K.D. (2002). Organizer activity of the polar cells during Drosophila oogenesis. Development 129: 5131-5140.

HORNE-BADOVINAC, S., BILDER, D. (2005). Mass transit: epithelial morphogenesis in the Drosophila egg chamber. Dev. Dyn. 232:559-574.

$\mathrm{KOCH}, \mathrm{M}$. (1929). Die postembryonale Entwicklung der Weiblichen Genitaldrusen und ihrer Ausfuhrungsgänge von Psychoda alternata Say. Z. Morph. Okol. Tiere 14: 1-36.

KUBRAKIEWICZ, J., BILINSKI, SZ.M., MAZURKIEWICZ, M. (1998). Diptera ovary structure and oogenesis in midges and flies. Folia Histochem. Cytobiol. 36: 197-203.

KUBRAKIEWICZ, J., JABLONSKA, A., MAZURKIEWICZ, M., BILINSKI, SZ.M. (2003). Differentiation and diversification of the follicular cells in flies: insight from the studies of the lower brachycerans' ovaries. Genesis 36: 214-224.

KRZEMINSKI, W., KRZEMINSKA, E. (2003). Triassic Diptera: description, revision and phylogenetic relations. Acta Zool. Cracov. 46: 153-184.

LEHMAN, R. (2001). Cell migration in invertebrates: clues from border and distal tip cells. Curr. Opin. Genet. Dev. 11: 457-463.

LIMA-DE FARIA, A. (1962). Metabolic DNA in Tipula oleracea. Chromosoma 13: 47.

LIMA-DE FARIA, A., MOSES, M.J. (1966). Ultrastructure and cytochemistry of metabolic DNA in Tipula. J. Cel/ Biol. 30: 177-192.

LÓPEZ-SCHIER, H. (2003). The polarization of the anteroposterior axis in Drosophila. BioEssays 25: 781-791.

MARGARITIS, L.H. (1985). Structure and physiology of the eggshell. In Kerkut, G.A., Gilbert, L.I., (Eds), Comprehensive Insect Biochemistry, Physiology and Pharmacology Pergamon Press, Oxford and New York, Vol. 1, pp 153-226

MAZURKIEWICZ, M., KUBRAKIEWICZ, J. (1998). Ontogenesis of the ovary in a moth midge, Tinearia alternata Say. (Diptera: Psychodidae). J. Morphol. 236: 167-177. 
MAZURKIEWICZ, M., KUBRAKIEWICZ, J. (2001). Intercellular cytoplasm transport during oogenesis of moth midge, Tinearia alternata Say (Diptera: Psychodidae). Folia Biol. (Krakow) 49: 205-213.

MAZURKIEWICZ, M., KUBRAKIEWICZ, J. (2002). Nucleolar activity of germ cells in polytrophic ovaries of crane flies (Diptera: Tipulidae). Ultrastructural and cytochemical studies. Folia Histochem. Cytobiol. 40(1): 47-50.

MAZURKIEWICZ, M., KUBRAKIEWICZ, J (2005). Differentiation and diversification of follicular cells in polytrophic ovaries of crane flies (Diptera: Nematocera: Tipulomorpha and Trichoceridae). Tiss. Cel/37: 367-377.

MCDONALD, K. (1984). Osmium ferrocyanide fixation improves microfilament preservation and membrane visualization in a variety of animal cells. J. Ultrastructure Res. 86: 107-118.

MONTELL, D.J. (2003). Border-cell migration: the race is on. Nat. Rev. Mol. Cell Biol. 4: 13-24.

MONTELL, D.J. (2006). The social lives of migrating cells in Drosophila. Curr. Opin. Genet. Dev. 16: 374-383.

NIEWIADOMSKA, P., GODT, D., TEPASS, U. (1999). DE-Cadherin is required for intercellular motility during Drosophila oogenesis. J. Cell Biol. 144: 533-547.

OOSTERBROEK, P., COURTNEY, G. (1995). Phylogeny of the nematocerous families of Diptera (Insecta). Zool. J. Linn. Soc. 115: 267-311.

PACQUELET, A., RøRTH, P. (2005). Regulatory mechanisms required for DEcadherin function in cell migration and other types adhesion. J. Cell. Biol. 170: 803-812.

RAY, R.P., SCHÜPBACH, T. (1996). Intercellular signalling and the polarization of body axes during Drosophila oogenesis. Genes Dev. 10: 1711-1723.

RIBEIRO, C., PETIT, V., AFFOLTER, M. (2003). Signaling system, guided cell migration, and organogenesis: insights from genetic studies in Drosophila. Dev. Biol. 260: 1-8.

ROCHA, T., DAVID, J.A.O., CAETANO, F.H. (2003). Ultramorphological feature of Telmatoscopus albipunctatus (Wilson) eggs (Diptera: Psychodidae). Acta
Microscopica Supp.12: 113.

RØRTH, P. (2002). Initiating and guiding migration: lesson from border cells Trends Cell Biol. 12: 325-331.

SCHOBER, M., PERRIMON, N. (2002). Unconventional ways to travel. Nat. Cell Biol. 4: E211-E212.

STEINHAUER, J., KALDERON, D. (2006). Microtubule polarity and axis formation in the Drosophila oocyte. Dev. Dyn. 235: 1455-1468.

TORRES, I.L., LÓPEZ-SCHIER, H., ST. JOHNSON, D. (2003). A Notch/Delta dependent relay mechanism polarity in Drosophila. Dev. Ce//5: 547-558.

TWORZYDLO, W., JABLONSKA, A., KISIEL, E., BILINSKI, S.M. (2005). Differing strategies of patterning of follicular cells in higher and lower brachycerans (Diptera: Brachycera). Genesis 43: 49-58

WARING, G.L. (2000). Morphogenesis of the eggshell in Drosophila. Int. Rev. Cytol. 198: 67-108.

WENZEL, F., GUTZEIT, H. O., ZISSLER, D. (1990). Morphogenesis of micropylar apparatus in ovarian follicles of the fungus gnat Bradysia tritici (syn. Sciara ocellaris). Roux's Arch. Dev. Biol. 199: 146-155.

WIEGMANN, B.M., YEATES, D.K., THORNE, J.L., KISHINO, H. (2003). Time flies, a new molecular time-scale for brachyceran fly evolution without a clock. Syst. Biol. 52 (6): 745-756.

XI, R., MCGREGOR, J.R. (2003). A gradient of JAK pathway activity patterns the anterior posterior axis of the follicular epithelium. Dev. Ce//4: 167-177.

YEATES, D.K. (2002). Relationship of extant lower Brachycera (Diptera): a quantitative synthesis of morphological characters. Zool. Scripta 31: 105-121.

ZARANI, F.E., MARGARITIS, L. (1985). The eggshell of Drosophila melanogaster. V. Structure and morphogenesis of the micropylar apparatus. Can. J. Zool. 64 2509-2519.

ZARANI, F.E., MARGARITIS, L. (1991). The eggshell of Drosophila melanogaster VII. Formation of the micropylar canal and the role of the paracrystalline structure. Rouxs Arch. Dev. Biol. 200: 95-103.

\section{Related, previously published Int. J. Dev. Biol. articles}

See our recent Special Issue Developmental Biology in Poland edited by Kloc, Maleszewski and Tarkowski at: http://www.ijdb.ehu.es/web/contents.php?vol=52\&issue =2-3

See our Special Issue Mammalian Reproduction \& Development in honor of Anne McLaren and edited by Brigid Hogan at: http://www.ijdb.ehu.es/web/contents.php?vol=45\&issue=3

Blood vessel/epicardial substance (bves) expression, essential for embryonic development, is down regulated by Grk/ EFGR signalling

Shengyin Lin, Debiao Zhao and Mary Bownes

Int. J. Dev. Biol. (2007) 51: 37-44

Stage-specific regulation of programmed cell death during oogenesis of the medfly Ceratitis capitata (Diptera, Tephritidae)

Athanassios D. Velentzas, loannis P. Nezis, Dimitrios J. Stravopodis, Issidora S. Papassideri and Lukas H. Margaritis

Int. J. Dev. Biol. (2007) 51: 57-66

Evolution of cis-regulation of the proneural genes.

Jean-Michel Gibert and Pat Simpson

Int. J. Dev. Biol. (2003) 47: 643-651

Paracrine actions of oocytes in the mouse preovulatory follicle.

A Salustri

Int. J. Dev. Biol. (2000) 44: 591-597

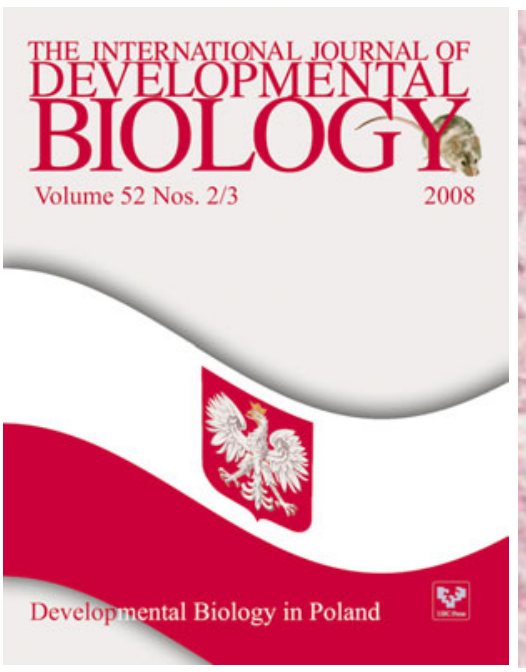

2006 ISI **Impact Factor $=3.577^{\star *}$

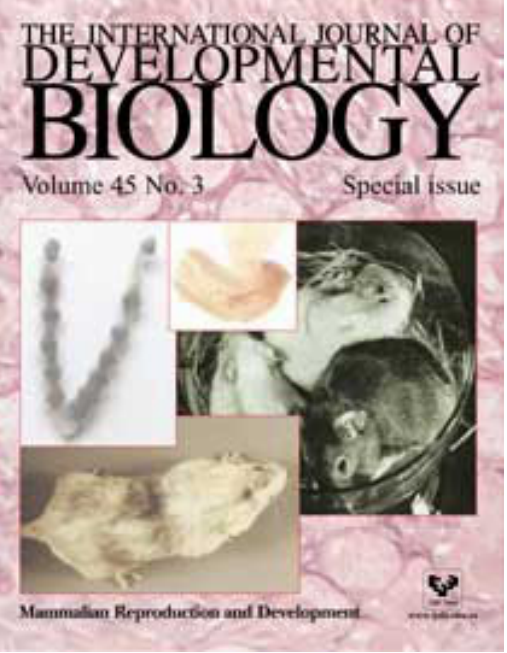

